\title{
Back to Basics, With a Twist
}

\author{
BY TOM GARRISON
}

WE ARE ALL TEACHERS. If you

are involved in pure or applied research you may not interact with students in the customary professorial way, but you are still a teacher. Our fast-moving interdisciplinary field guarantees you will be called upon to transmit information to groups of people. Whether they are peers, managers, or students, you will need to teach them.

And you know how to do that-you have been doing it all your professional life. You are not the person whose slides (slides?) are in the tray backwards and upside-down. You are not the person who can't find the microphone's "on" button. You are not the person who doesn't have the right cord for the laptop. Of course not. Those are obvious problems that a little foresight can solve. In this column I will dig a bit deeper to explore some subtle failures that plague presentations. (For more tips on how to give presentations, see the TOS booklet Scientifically Speaking. The booklet can be downloaded from the TOS web site at http://www.tos.org/resources/publications/ sci_speaking.html.)

Let's start with some obvious points that are often not obvious enough:

- Your presentation (to 5 people or 500) should be a smooth progression of ideas. Build a logic pyramid and ask rhetorical questions at sensitive places in the development. Questions will not generally be volunteered by listeners during a talk attended by more than
20 people even if they're encouraged to ask. Presentations therefore must be anticipative of questions before they arise, and as linear as possible.

- Can everyone see and hear? Are you sure? Your best plan of action is to visit the place where you will be presenting while someone else is speaking. Try to move around unobtrusively to hear the sound system. If a sound system is not to be used, make a mental note of how loud you will need to speak to be understood. What about the image on the screen (if any). How bright is it? Is it viewable from an angle? Does noise from the projector or air conditioner or adjacent hallway intrude noticeably? Are there enough chairs for the intended audience? Do you know how to dim the lights?

- Beware of high information density in PowerPoint presentations. Limit each slide to 10 words and one image. Make transitions smooth-don't say "now let's look at some slides." And (a personal plea from an old professor who has truly had his fill of this) please don't use whole paragraphs in 12-point type and cute typefaces and tumbling letters and bizarre backgrounds and distracting screen transitions. Just the data, please, in a clean and non-distracting form. If you spend more time selecting typefaces than contemplating content, be very afraid. (There! I feel much better now!)

- Always repeat a question asked by a participant so everyone can hear, but feel free to change it around a bit to suit your purposes. Say, "good question" or "interesting idea” after you rephrase it, even if it's a certified stinker. Encourage questions. Ask them of the group. Keep participants thinking.

- Start and finish on time. Who has not fumed at the back of the room waiting for the last speaker to make "just one more point?" Makes me crazy.

And then there are more subtle tricks:

- Arrive early and introduce yourself. This serves two purposes: (1) it calms you down before your presentation, and (2) it prepares a bridge between you and your group. Even if you know most of the people to whom you will speak, renewing acquaintances will lead to a smoother presentation. The subtle part? You will have read up on their current research or business interests or work with students, and you may be able to work that into your presentation.

- Don't start with a joke. Just don't.

- Don't talk only to a chosen few. They may be your chums, but your inside jokes will be lost on the larger audience. No subtlety here-just courtesy.

- Dress properly. A coat and tie or cocktail dress may not be appropriate, but you represent your field and institu-

Tom Garrison (tomgarrison@sbcglobal. net) is an instructor at Orange Coast College, Costa Mesa, CA, USA. 
tion and your latest "Green Day" concert T-shirt may not reflect well on either. Subtle? You can't go wrong with a long-sleeved white shirt.

- Rehearse. Run that PowerPoint 15 times and know what's coming up next. Talk to the chair in the hotel room. What's subtle about that? You'll quickly feel ridiculous talking to the furniture, and the humor in the situation will be a good counterpoise to the presentation itself.

- Remember teaching's most important dictum: "Tell them what you're going to tell them, then tell them, then tell them what you told them." Subtle idea: Write a brief outline of your presentation on an easily visible object (white board, easel) and let it sit there. Your group will know where you are and where you're headed.

- Read your notes to your audience and you'll lose your audience. The only thing worse is reading your overly-dense PowerPoint slides to the group as you show them. Your lectern prompts should be a few words on one page, and an easily accessible copy of the posted presentation outline.

- In a large group, have someone identify a few people you don't know. When you recognize them or point out their work as it applies to your topic, they'll be pleased and astonished. This works dangerously well with large groups of undergraduates in a lecture hall. My course assistants identify the names and locations of five or six random students out of my 550 student group, and I call on them by name to answer questions during the lecture. At the end of this stunt, my lecture class is absolutely convinced
I know all their names, and pays more diligent attention!

- Duds must be dissected for fault; they must never be shrugged off. If a teaching session crashed and burned, if participants laughed at the wrong time, if your peers smelled death, find out why. Teaching is Darwinian: The best techniques are saved; the things that don't work are identified and euthanized before they reach reproductive age.

- Make sure your managers (administrators, bosses, deans) know what you're doing. Copies of the program, or even of the lecture itself, should find their way to their desks. This is not necessarily a subtle form of selfadvertising - it is, rather, a way to show your work in the larger context of your field. a fascinated involvement with it...a sort of intellectual affair. The very thought of the idea is positive, encouraging, stimulating, wonderful to consider. Romance is Whitehead's word for this first stage. Second, the person becomes precise with the ideas...detailed, elaborated, explored. Not surprisingly, Whitehead called this phase precision. Third, the person pops his or her head out of the bog of detail and trivia and begins to relate the fine points of the topic to the world at large... Whitehead's generalization.

We can employ our modern hightech presentation tools most effectively in the first stage, with some effectiveness in the second stage, and almost never in the third stage. Generalization is the province of discussion, lecture/discussion, writing, and small seminars. Standard lecture is hard to justify here, but

\section{Whether they are peers, managers, or students, you will need to teach them.}

These are details, and they must fit into the larger picture. What do you really want to transmit? After you have committed to a speaking engagement, long before you cash in those frequent flyer miles, you need to sit quietly and think about the larger picture-you need a "so what" moment.

The master of "so what" was Alfred North Whitehead, British mathematician, philosopher, and educator. He was convinced that everyone learns in three stages. First, the person becomes interested in the topic. He or she goes through we have been generalizing in lectures since Plato so it will be hard to stop now. It may be fashionable to be anti-lecture these days, but a well-done lecture (i.e., well planned and well presented) is hard to beat for overall effectiveness.

Now start at the end. Imagine what your final generalizations will be. Work toward the front of your presentation, adding imaginative examples and illustrations as you go.

Now go teach, even if you don't consider yourself a teacher. ⿷匚 